\title{
Region-Specific Regulation of Glutamic Acid Decarboxylase (GAD) mRNA Expression in Central Stress Circuits
}

\author{
Garrett Bowers, ${ }^{1}$ William E. Cullinan, ${ }^{2}$ and James P. Herman ${ }^{1}$ \\ ${ }^{1}$ Department of Anatomy and Neurobiology, University of Kentucky Medical Center, Lexington, Kentucky 40536-0084, \\ and ${ }^{2}$ Department of Basic Health Sciences, Marquette University, Milwaukee, Wisconsin 53233
}

\begin{abstract}
Neurocircuit inhibition of hypothalamic paraventricular nucleus (PVN) neurons controlling hypothalamo-pituitary-adrenocortical (HPA) activity prominently involves GABAergic cell groups of the hypothalamus and basal forebrain. In the present study, stress responsiveness of GABAergic regions implicated in HPA inhibition was assessed by in situ hybridization, using probes recognizing the GABA-synthesizing enzyme glutamic acid decarboxylase (GAD65 and GAD67 isoforms). Acute restraint preferentially increased GAD67 mRNA expression in several stress-relevant brain regions, including the arcuate nucleus, dorsomedial hypothalamic nucleus, medial preoptic area, bed nucleus of the stria terminalis (BST) and hippocampus (CA1 and dentate gyrus). In all cases GAD67 mRNA peaked at $1 \mathrm{hr}$ after stress and returned to unstimulated levels by $2 \mathrm{hr}$. GAD65 mRNA upregulation was only observed in the BST and dentate gyrus. In contrast, chronic intermittent stress increased GAD65 mRNA in the anterior hypothalamic area, dorsomedial nucleus, medial preoptic area, suprachiasmatic nucleus, ante-
\end{abstract}

rior BST, perifornical nucleus, and periparaventricular nucleus region. GAD67 mRNA increases were only observed in the medial preoptic area, anterior BST, and hippocampus. Acute and chronic stress did not affect GAD65 or GAD67 mRNA expression in the caudate nucleus, reticular thalamus, or parietal cortex. Overall, the results indicate preferential upregulation of GAD in central circuitry responsible for direct (hypothalamus, BST) or multisynaptic (hippocampus) control of HPA activity. The distinct patterns of GAD65 and GAD67 by acute versus chronic stress suggest stimulus duration-dependent control of GAD biosynthesis. Chronic stress-induced increases in GAD65 mRNA expression predict enhanced availability of GAD65 apoenzyme after prolonged stimulation, whereas acute stress-specific GAD67 upregulation is consistent with de novo synthesis of active enzyme by discrete stressful stimuli.

Key words: acute stress; chronic stress; hypothalamus; hippocampus; preoptic area; hypothalamo-pituitary-adrenocortical axis
Physiological responses to stress typically demand changes in energy use, cardiovascular tone, endocrine status, and arousal level, which are driven in large part by adrenocortical glucocorticoid hormones. Release of glucocorticoids is initiated by a discrete set of executive neurons localized in the hypothalamic paraventricular nucleus (PVN) (Antoni, 1986; Whitnall, 1993). These neurons synthesize and secrete a cocktail of neuropeptides that promote release of adrenocorticotrophic hormone (ACTH) and, subsequently, glucocorticoids.

Efficient inhibition of glucocorticoid secretion is required to limit the magnitude and duration of stress responses at the level of the PVN. This is accomplished by both neuronal inhibitory circuitry and blood-borne glucocorticoid negative feedback. Central circuitry regulating neuronal inhibition of the PVN prominently involves the hippocampus. This region is known to play a role in the inhibition of basal ACTH secretagog expression and in limiting the duration of stress-induced glucocorticoid secretion (Herman et al., 1989; Jacobson and Sapolsky, 1991). Inhibitory effects of hippocampal action seem to be driven by the ventral

Received March 3, 1998; revised May 4, 1998; accepted May 7, 1998.

This work is sponsored by MH 49698 (J.P.H.) and by National Science Foundation Grant DBI-9424220 (G.B.). We would like to thank Dr. Allan Tobin for the GAD65 and GAD67 cDNAs and Mark Dolgas and Xiaohang Wang for expert technical assistance.

Correspondence should be addressed to Dr. James P. Herman, Department of Anatomy and Neurobiology, University of Kentucky Medical Center, 800 Rose Street, Lexington, KY 40536-0084.

Copyright (C) 1998 Society for Neuroscience $0270-6474 / 98 / 185938-10 \$ 05.00 / 0$ subiculum, because effects of total hippocampectomy on PVN corticotropin-releasing hormone (CRH) mRNA expression and stress duration can be mimicked by lesions confined to this region (Herman et al., 1995).

Anatomical data do not support a direct connection between limbic neurons and the medial parvocellular PVN. However, ventral subiculum projects to a number of forebrain regions that in turn innervate this region, including the bed nucleus of the stria terminalis (BST), medial preoptic area, dorsomedial hypothalamic nucleus, and anterior hypothalamic area (Cullinan et al., 1993). Combined anterograde-retrograde tracing studies indicate that ventral subiculum efferents contact BST, preoptic area, dorsomedial hypothalamic, and anterior hypothalamic area neurons that are retrogradely labeled by PVN injections of Fluorogold (Cullinan et al., 1993). Notably, the vast majority of these PVNprojecting neurons contain the inhibitory neurotransmitter GABA (Cullinan et al., 1993). Because projection neurons of ventral subiculum are likely to use excitatory amino acid transmitters (glutamate and aspartate) (Walaas and Fonnum, 1980), the anatomical data suggest the possibility of a bisynaptic subiculum-PVN connection, essentially switching excitatory hippocampal signals into inhibition at the PVN.

This hypothesis suggests that PVN-projecting GABAergic populations are critical components of hypothalamo-pituitaryadrenocortical (HPA) inhibition of stress responses and predicts that these cell groups should be activated by stressful stimuli. In accordance with this notion, recent studies indicate that neurons in the BST and hypothalamus increase cFOS expression after 
acute stress exposure (Cullinan et al., 1995; Sawchenko et al., 1996), consistent with stress activation. Furthermore, doublelabel studies indicate that a large proportion of stress-activated neurons in these PVN-projecting regions express the GABAergic marker glutamic acid decarboxylase (GAD) mRNA (Cullinan et al., 1996). Involvement of GABA in HPA inhibition is supported by microinjection studies, which document reduced PVN neuronal activity and attenuated corticosterone (CORT) secretion after local application of GABAergic drugs (Boudaba et al., 1996; W. E. Cullinan, unpublished observations). To address activation of GABAergic neurocircuits by stress directly, the present study assesses stress regulation of GAD isoform (GAD65/GAD67) mRNA expression in brain regions responsible for monosynaptic or disynaptic control of HPA activation.

\section{MATERIALS AND METHODS}

Animals. Male Sprague Dawley rats initially weighing between 240 and $320 \mathrm{gm}$ were included in both studies. All rats were housed three per cage on a $12 \mathrm{hr}: 12 \mathrm{hr}$ light/dark cycle with food and water available ad libitum.

Acute stress protocol. Animals were divided into three groups. Unstressed animals $(n=7)$ were not exposed to stress before death and thus represented the control group. The $60 \min$ group $(n=7)$ was exposed to $1 \mathrm{hr}$ of restraint stress in plastic restraint tubes and killed immediately after the stress. The $120 \mathrm{~min}$ group $(n=7)$ was exposed to the same 60 min restraint stressor, returned to their home cages, and subsequently killed 1 hr later.

Chronic stress protocol. Animals were divided into two groups. The chronic intermittent stress group $(n=6)$ was subjected to a $15 \mathrm{~d}$ variable intermittent stress paradigm using the following stressors:

(1) Restraint: rats were placed in plastic restraint cages for $2 \mathrm{hr}$.

(2) Isolation: rats were housed in individual cages until the next stress period.

(3) Cold restraint: rats were placed in plastic restraint cages in a cold room $\left(4^{\circ} \mathrm{C}\right)$ for $2 \mathrm{hr}$.

(4) Crowding: rats were placed six per cage until the next stress period.

(5) Rotation/crowding: rats were placed six per cage on an orbit shaker and rotated for $2 \mathrm{hr}$.

(6) Swim: rats were placed in an aquarium filled with $28-32^{\circ} \mathrm{C}$ water for $40 \mathrm{~min}$.

(7) Cold swim: rats were placed in an aquarium filled with $15-18^{\circ} \mathrm{C}$ water for $10 \mathrm{~min}$.

Stressed rats were exposed to two stressors per day, varied randomly among the above list. Control rats $(n=6)$ were individually handled for 1 min each time the experimental group was stressed.

All rats in both the acute and chronic studies were killed by rapid decapitation between the hours of 9 and 11 A.M. All brains were removed and frozen in isopentane cooled on dry ice at -40 to $-50^{\circ} \mathrm{C}$. Core blood samples were collected in heparinized tubes and centrifuged at $1500 \times g$, and plasma samples were frozen at $-20^{\circ} \mathrm{C}$. Brains were stored at $-80^{\circ} \mathrm{C}$ until processing. All brains were sectioned in series at 15 $\mu \mathrm{m}$ using a Bright-Hacker cryostat, mounted on Superfrost Plus slides, and stored at $-20^{\circ} \mathrm{C}$.

In situ hybridization. Series of tissue sections were taken from the $-20^{\circ} \mathrm{C}$ freezer and fixed in $4 \%$ phosphate-buffered paraformaldehyde for $10 \mathrm{~min}$. Slides were rinsed twice in $5 \mathrm{~mm}$ potassium PBS (KPBS) for 5 min, twice in $5 \mathrm{mM} \mathrm{KPBS}$ with $0.2 \%$ glycine for $5 \mathrm{~min}$, and twice in KPBS for $5 \mathrm{~min}$. Slides were then acetylated in $0.1 \mathrm{M}$ triethanolamine, $\mathrm{pH}$ 8.0 , with $0.25 \%$ acetic anhydride for $10 \mathrm{~min}$. Slides were rinsed twice in $2 \times$ SSC for 5 min and dehydrated through graded alcohols.

Antisense rat GAD65 and GAD67 probes were produced by in vitro transcription using $\left[{ }^{33} \mathrm{P}\right]$ UTP. Plasmids containing the GAD65 (courtesy of A. Tobin, University of California, Los Angeles) insert were linearized with StuI and transcribed with T3 RNA polymerase. Plasmids containing the GAD67 insert (courtesy of A. Tobin, University of California, Los Angeles) were linearized with HincII and transcribed with T3 RNA polymerase. The transcription reaction consisted of $10 \times$ transcription buffer that contained $125 \mu \mathrm{Ci}$ of $\left[{ }^{33} \mathrm{P}\right] \mathrm{UTP}, 200 \mu \mathrm{M}$ ATP, CTP, and GTP, $10 \mu \mathrm{M}$ cold UTP, $100 \mathrm{~mm}$ dithiothreitol, $40 \mathrm{U} / \mu \mathrm{l}$ placental RNase inhibitor, and $20 \mathrm{U} / \mu \mathrm{l}$ T3 RNA polymerase. The mixture was incubated for $90 \mathrm{~min}$ at $37^{\circ} \mathrm{C}$, and probe was separated from free nucleotides by ammonium acetate precipitation.

\begin{tabular}{|c|c|c|}
\hline Group & $\begin{array}{l}\text { ACTH } \\
(\mathrm{pg} / \mathrm{ml})\end{array}$ & $\begin{array}{l}\text { Corticosterone } \\
(\mathrm{ng} / \mathrm{ml})\end{array}$ \\
\hline Unstressed & $73.5 \pm 25.1$ & $4.3 \pm 2.5$ \\
\hline $60 \mathrm{~min}$ & $179.9 \pm 29.5^{*}$ & $266.8 \pm 61.1^{*}$ \\
\hline $120 \mathrm{~min}$ & $50.9 \pm 9.1$ & $9.7 \pm 2.1$ \\
\hline
\end{tabular}

*Significant differences.

Probes were diluted in hybridization buffer to yield $\sim 1,000,000 \mathrm{cpm} / 50$ $\mu \mathrm{l}$ of buffer. Diluted aliquots of $50 \mu \mathrm{l}$ were applied to each slide, with slides coverslipped and incubated overnight at $55^{\circ} \mathrm{C}$ in chambers containing filter paper moistened with $50 \%$ formamide. Coverslips were then removed in $2 \times \mathrm{SSC}$, and slides were incubated in RNase A $(100 \mu \mathrm{g} / \mathrm{ml})$ for $30 \mathrm{~min}$ at $37^{\circ} \mathrm{C}$. Slides were briefly rinsed in $2 \times \mathrm{SSC}$ and washed three times in $0.2 \times$ SSC for $10 \mathrm{~min}$, followed by a $1 \mathrm{hr}$ bath in $0.2 \times \mathrm{SSC}$ at $65^{\circ} \mathrm{C}$. Slides were dehydrated through graded alcohols, exposed to Kodak Biomax MR-2 film for 3-6 d, and subsequently dipped in Kodak (NTB2) emulsion. Dipped slides were stored at $4^{\circ} \mathrm{C}$ in light-tight boxes for $25 \mathrm{~d}$, developed in Kodak D-19 developer, and coverslipped with DPX mountant.

Image analysis. Semiquantitative analyses of in situ hybridization films were performed with Macintosh-based NIH Image 1.59 software. Sections from control and experimental animals were matched for rostrocaudal level, and regions of interest were captured. Anatomical areas of interest were determined from the Paxinos and Watson (1986) atlas and sampled manually. The rostrocaudal levels for BST and hypopthalamic regions selected for analysis were based on distinctions outlined in the Paxinos and Watson atlas as follows: anteromedial BST (encompassing atlas divisions BSTMA) and anterodorsal BST (encompassing atlas divisions BSTLD, BSTLJ, and BSTI), plates 19-20; posterior intermediate BST, posterolateral BST, and medial preoptic area, plates 21-22; suprachiasmatic nucleus, plates 23-24; anterior hypothalamic area, plates 24-25; arcuate nucleus, plates 25-29; and dorsomedial hypothalamus, plates 29-30 (Paxinos and Watson, 1986). Background signal was determined by sampling nonhybridized regions of each section (white matter). Background signal was subtracted from raw gray level measures, and the resulting regional corrected gray level measures were averaged for each animal.

Assessment of grain density over neurons of the peri-PVN zone and perifornical region was performed by a semiautomated computerized grain-counting protocol. Images of lightly counterstained neurons of the peri-PVN region and perifornical nucleus were captured at $63 \times$, through a blue Wratten filter (no. 47). This filter reduced the intensity of the counterstain and allowed grains to be clearly distinguished from Nisslcounterstained cellular profiles. Cellular profiles were manually sampled, and area determinations were made within Image 1.59. Images were then thresholded to visualize grains only, and area determinations were repeated. The sampling template was then moved to an unhybridized region of tissue to establish background grain area. Results were expressed as the percent of area occupied by grains, calculated as:

$$
\% \text { area }=\frac{-(\text { background area occupied by grains })}{\text { total area of sampling template }} \times 100 .
$$

Image processing. Images were obtained from x-ray film autoradiographs or negatives using a Polaroid SprintScan 35 slide scanner and Adobe Photoshop 4.0 software. Images imported into Photoshop were contrast and brightness adjusted and assembled into composite images (Figs. 1,2).

Plasma hormone assays. Plasma from trunk blood samples was processed for radioimmunoassay (RIA) for CORT and ACTH. Plasma CORT and ACTH levels were obtained via RIA kits using ${ }^{125}$ I tracers from ICN Biomedicals (Cleveland, $\mathrm{OH}$ ) and IncSTAR, respectively.

Data analysis. Acute stress data were analyzed by one-way ANOVA, with time differences then evaluated by Duncan's multiple range test. Chronic stress data were analyzed by unpaired Student's $t$ test.

\section{RESULTS \\ Physiological impact of acute and chronic intermittent stress}

Effects of restraint on HPA activation are summarized in Table 1. 


\begin{tabular}{|c|c|c|c|c|c|c|}
\hline Group & $\begin{array}{l}\text { АCTH } \\
(\mathrm{pg} / \mathrm{ml})\end{array}$ & $\begin{array}{l}\text { CORT } \\
(\mathrm{ng} / \mathrm{ml})\end{array}$ & $\begin{array}{l}\text { Adrenal wt. } \\
(\mathrm{mg})\end{array}$ & $\begin{array}{l}\text { Adrenal wt. } \\
(\mathrm{mg} / 100 \mathrm{gm})\end{array}$ & $\begin{array}{l}\text { Thymus wt } \\
\text { (mg) }\end{array}$ & $\begin{array}{l}\text { Thymus wt } \\
\text { (mg/100gm) }\end{array}$ \\
\hline Handled & $50.4 \pm 2.0$ & $52.4 \pm 10.3$ & $37.0 \pm 1.5$ & $12.7 \pm 4.0$ & $436 \pm 25$ & $149.6 \pm 4.7$ \\
\hline Stress & $79.6 \pm 17.9$ & $49.6 \pm 23.5$ & $42.4 \pm 1.0^{*}$ & $16.5 \pm 4.0^{*}$ & $336 \pm 22^{*}$ & $130.4 \pm 8.4$ \\
\hline
\end{tabular}

*Significant differences. wt, Weight.

As expected, there was a significant effect of restraint on both $\operatorname{ACTH}\left[F_{(2,19)}=6.76 ; p<0.05\right]$ and CORT $\left[F_{(2,19)}=19.46 ; p<\right.$ $0.05]$ secretion. Effects were carried by significant elevations in both ACTH and CORT at the $60 \mathrm{~min}$ time point after stress (Duncan's multiple range test).

Chronic intermittent stress data are summarized in Table 2. There was no overall effect of stress on basal ACTH or CORT secretion, likely reflecting the fact that animals were killed $16 \mathrm{hr}$ after the last stressor. A significant long-term impact of chronic stress is verified by adrenal hypertrophy [raw adrenal weight, $t(10)=5.50$ and $p<0.05$; adrenal weight $/ 100$ gm of body weight, $t(10)=7.26$ and $p<0.05]$ and decreased thymus weight [raw thymus weight, $t(10)=2.96$ and $p<0.05$ ]. Effects of stress on thymus weight/100 gm of body weight approached statistical reliability $[t(10)=1.99 ; p=0.07]$.

\section{Localization of GAD65 and GAD67 mRNA}

In situ hybridization analysis indicated that GAD65 and GAD67 mRNAs were highly abundant in numerous CNS loci (Fig. 1). Of particular relevance to the present study, both GAD65 and GAD67 mRNAs were present in numerous PVN-projecting nuclei, including the medial preoptic area, anterior hypothalamic area, dorsomedial hypothalamic nucleus, arcuate nucleus, and the anterodorsal, anteromedial, posteromedial, and posterointermediate divisions of the BST. In addition, significant hybridization was also seen in the lateral septum, posterolateral BST, and suprachiasmatic nuclei, regions projecting to the immediate surround of the PVN. Neurons in close proximity to the PVN (peri-PVN zone and perifornical nucleus) also express high levels of both GAD mRNAs (Fig. 2).

GAD65 and GAD67 mRNAs were highly expressed outside the hypothalamic-basal forebrain continuum. In the hippocampus, a region that has been repeatedly implicated in HPA regulation, GAD65- and 67-positive neurons were scattered throughout the CA1 and CA3 subfields and in the dentate gyrus (Fig. 1C), consistent with localization to interneurons. Positive hybridization was also observed in neurons throughout the cerebral cortex and striatum. Robust expression was observed in the thalamic reticular nucleus and anteroventral thalamic nucleus. In all cases, overlap of regions hybridized for GAD65 and GAD67 was extensive, suggesting a high degree of colocalization (Esclapez et al., 1993; Feldblum et al., 1993).

\section{Acute stress}

Semiquantitative in situ hybridization was used to assess changes in GAD65 mRNA expression after acute restraint stress. Results of densitometric analysis are summarized in Figure $3 A$. Exposure to acute restraint elevated GAD65 mRNA expression in the anteromedial subnucleus of the bed nucleus of the stria terminalis. However, GAD65 mRNA expression was not affected in any other subdivisions of the bed nucleus of the stria terminalis or in any region of the hypothalamus. No effects of stress were observed in reticular thalamus or caudate nucleus.

Expression of GAD65 mRNAs in the peri-PVN region and
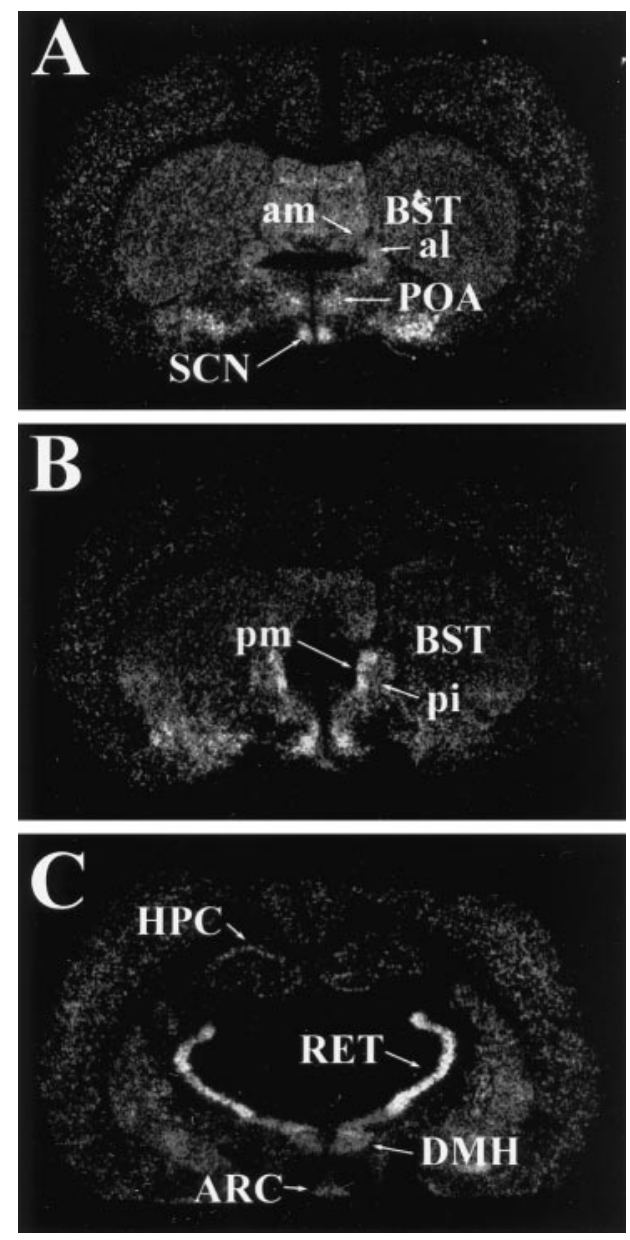

Figure 1. Localization of GAD65 mRNA in central stress circuits. GAD65 mRNA is expressed in numerous forebrain stress-relevant nuclei, including the anteromedial $(\mathrm{am})$, anterolateral $(\mathrm{al})$, posteromedial $(\mathrm{pm})$, and posterointermediate $(p i)$ subdivisions of the bed nucleus of the stria terminalis; the medial and lateral preoptic area $(P O A)$; the suprachiasmatic nucleus $(S C N)$; the dorsomedial hypothalamic nucleus $(D M H)$; the arcuate nucleus $(A R C)$; and the hippocampal formation (HPC). GAD65 mRNA is also localized to additional regions not implicated in stress regulation, such as the reticular thalamic nucleus (RET). Scale bar, $1 \mathrm{~mm}$.

perifornical nucleus were assessed by semiautomated grain density measures (Fig. 3B). There was a significant effect of stress on GAD65 mRNA expression in the immediate surround of the PVN $\left[F_{(2,19)}=4.04 ; p<0.05\right]$; this effect was carried by a decrease in the 120 min group relative to unstressed controls $(p<0.05)$. There was no effect of stress on the perifornical cell group.

Acute stress did not affect expression of GAD65 mRNA in hippocampal pyramidal cell layers or in parietal cortex (Fig. 3C). However, significant effects of acute stress on GAD65 expression were observed in the dentate gyrus $\left[F_{(2,18)}=4.95 ; p<0.05\right]$. Post 

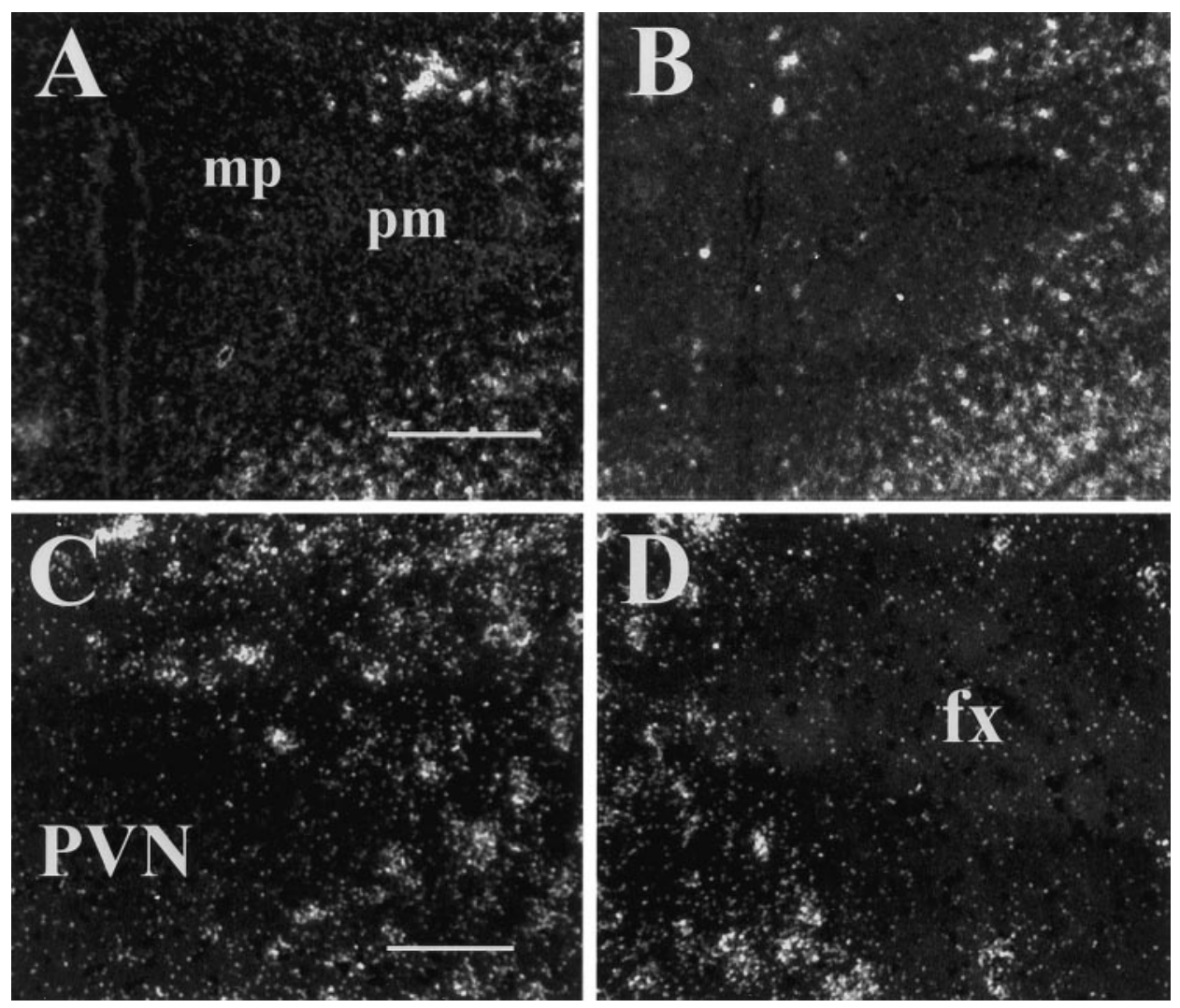

Figure 2. Localization of GAD65 $(A)$ and GAD67 $(B)$ mRNAs in the immediate surround of the PVN. Note that very few GAD mRNA-expressing neurons are present in the medial parvocellular $(\mathrm{mp})$ or posterior magnocellular ( $p m$ ) PVN; however, aggregates of GAD-positive neurons can be observed to cluster just outside the PVN proper $(A, B)$ and in the neighboring perifornical region. Higher power photomicrographs indicate high levels of GAD65 $(C$, $D$ ) and GAD67 (data not shown) mRNA in scattered neurons in both regions. $f x$, Fornix. Scale bars: $A, B, 200 \mu \mathrm{m} ; C, D, 100 \mu \mathrm{m}$.

hoc analysis (Duncan's multiple range test) revealed significant increases in the 60 min stress group relative to unstressed rats.

In contrast with GAD65, significant effects of stress on GAD67 mRNA were observed in several regions of the hypothalamus, including the medial preoptic area $\left[F_{(2,19)}=5.17 ; p<0.05\right]$, arcuate nucleus $\left[F_{(2,19)}=12.56 ; p<0.05\right]$, and dorsomedial hypothalamic nucleus $\left[F_{(2,19)}=6.11 ; p<0.05\right]$ (Fig. $4 A$ ). In all cases, expression was increased only at the $60 \mathrm{~min}$ time point after stress. No changes in GAD67 expression were observed in the anterior hypothalamic area or suprachiasmatic nucleus. Within the BST, GAD67 mRNA was increased in the anteromedial $\left[F_{(2,18)}=6.36 ; p<0.05\right]$ and anterodorsal $\left[F_{(2,18)}=4.65 ; p<\right.$ $0.05]$ subnuclei. No changes were observed in the posteromedial and posterointermediate or posterolateral subdivisions of the BST. Similarly, no changes in cellular GAD67 mRNA expression were observed in the peri-PVN region or perifornical nucleus (Fig. 4B).

Increased GAD67 mRNA was also observed in the hippocampus (Fig. 4C). Significant effects of stress on GAD67 expression were observed in CA1 $\left[F_{(2,18)}=5.82 ; p<0.05\right]$ and dentate gyrus $\left[F_{(2,18)}=6.61 ; p<0.05\right]$. In both cases, $60 \mathrm{~min}$ groups were distinguished from unstressed animals $(p<0.05)$. No stress effects were observed in the CA3, parietal cortex, reticular thalamic nucleus, or caudate nucleus.

\section{Chronic stress}

In contrast to the results of the acute stress experiments, chronic stress primarily affected GAD65 mRNA expression (Figs. 5, 6). GAD65 mRNA was increased in several hypothalamic nuclei, including the medial preoptic area $[t(9)=3.92 ; p<0.05]$, anterior hypothalamic area $[t(9)=2.35 ; p<0.05]$, and dorsomedial hypothalamic nucleus $[t(9)=2.51 ; p<0.05]$ (Fig. 5A). GAD65 mRNA expression was also increased in the anterodorsal $[t(10)=5.07 ; p<0.05]$ and anteromedial $[t(10)=4.83 ; p<0.05]$ BST; no changes were observed in the posterolateral or posteromedial and posterointermediate subnuclei. GAD65 hybridization density was increased over neurons in the peri-PVN region $[t(8)$ $=2.28 ; p<0.05]$ and in the perifornical nucleus $[t(8)=2.71 ; p<$ 0.05] (Fig. 5B). No changes in GAD65 mRNA expression were observed in the hippocampus (Fig. 5C), caudate, parietal cortex, or reticular thalamic nucleus.

Chronic stress-induced changes in GAD67 mRNA were considerably more limited than that in GAD65 mRNA (Fig. 6). Increased levels of GAD67 mRNA were observed in the medial preoptic area $[t(9)=2.21 ; p=0.05]$ and in the anteromedial $[t(9)=2.48 ; p<0.05]$ and anterodorsal $[t(9)=2.37 ; p<0.05]$ subnuclei of the BST (Fig. 6A). In contrast, no GAD67 changes were seen in any other region of the hypothalamus proper or in individual neurons of the peri-PVN region and perifornical nucleus (Fig. 6B). GAD67 mRNA was upregulated by stress in the hippocampal subfield CA3 $[t(9)=4.64 ; p<0.05]$ and in the dentate gyrus $[t(9)=2.22 ; p=0.05]$ (Fig. $6 C$ ). No changes in GAD67 mRNA were observed in CA1, cortex, caudate nucleus, or reticular thalamus.

\section{DISCUSSION}

\section{GAD65 and GAD67 mRNA regulation in PVN-projecting nuclei}

The present study is consistent with the hypothesis that PVNprojecting GABAergic neurons are instrumental in central stress regulation. Expression of GAD65 and GAD67 mRNA was markedly increased by stress in numerous hypothalamic and BST cell groups known to have efferents to the medial parvocellular PVN. These include the medial preoptic area, dorsomedial hypothalamic nucleus, arcuate nucleus, peri-PVN region, perifornical 

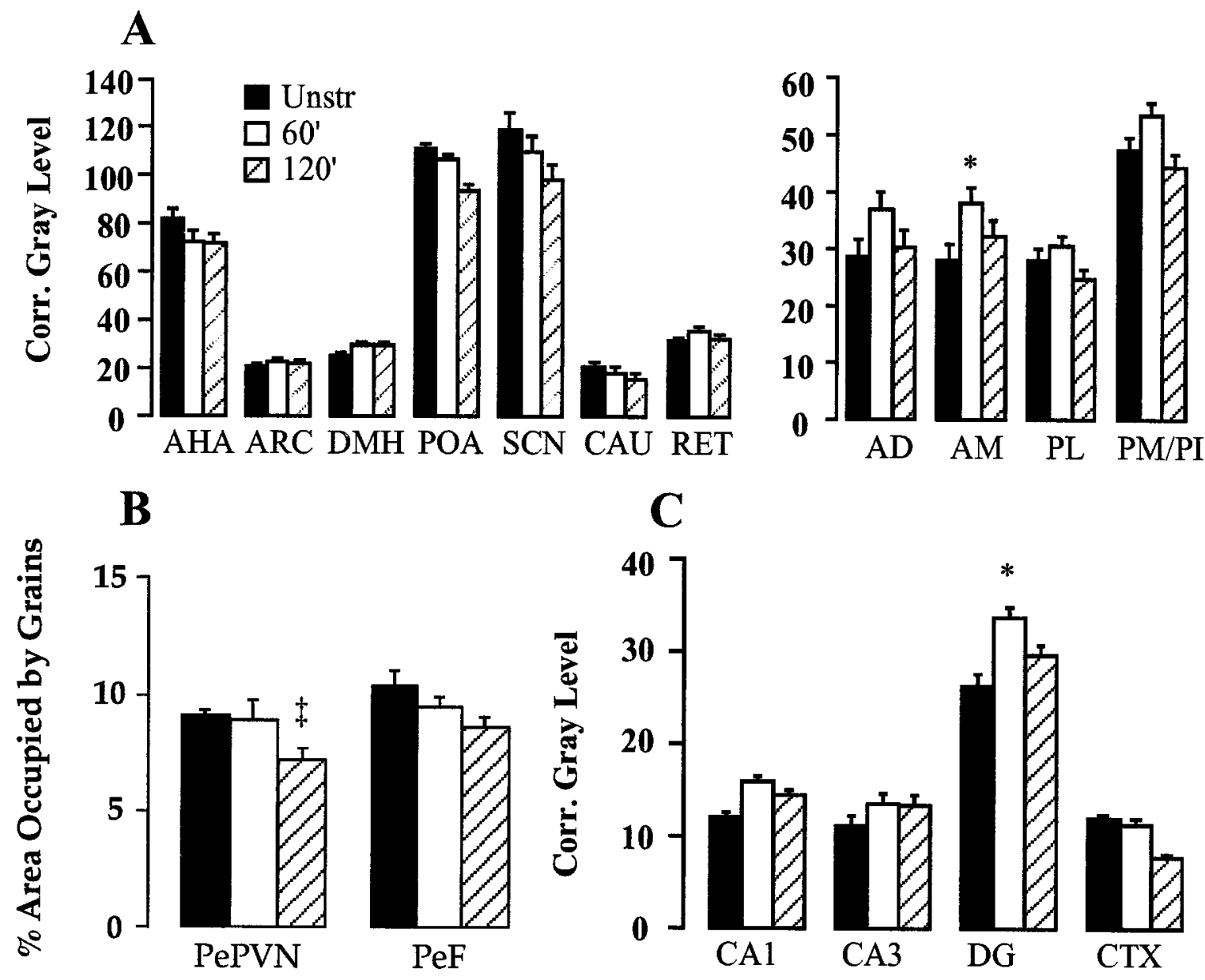

Figure 3. Semiquantitative assessment of the effect of acute restraint on GAD65 mRNA expression in forebrain stress-relevant nuclei. $A$, No changes in GAD65 mRNA expression were observed in the anterior hypothalamic nucleus $(A H A)$, arcuate nucleus $(A R C)$, dorsomedial hypothalamic nucleus $(D M H)$, medial preoptic area $(P O A)$, suprachiasmatic nucleus $(S C N)$, caudate nucleus $(C A U)$, and reticular thalamic nucleus $(R E T)$. GAD65 mRNA is elevated $60 \mathrm{~min}$ after stress in the anteromedial subnucleus $(A M)$ of the bed nucleus of the stria terminalis but is not altered in the anterodorsal $(A D)$, posterolateral $(P L)$, or posteromedial and posterointermediate subnuclei $(P M / P I)$. $B$, Grain density analysis was used to assess GAD65 mRNA expression in the peri-PVN region $(P e P V N)$ and the perifornical nucleus $(P e F)$. Reduced grain density was observed over neurons in the peri-PVN region $120 \mathrm{~min}$ after stress exposure. $C$, Densitometric analysis of GAD65 mRNA in the hippocampus revealed significant elevation in dentate gyrus $(D G) 60$ min after stress exposure. CTX, Parietal cortex; Unstr, Unstressed.

nucleus, and anterior subnuclei of the BST. Importantly, these regions have all been implicated in central control of the HPA axis. The medial preoptic area is known to inhibit ACTH and corticosterone secretion and is a potential site of glucocorticoid negative feedback inhibition of the HPA axis (Viau and Meaney, 1996). The dorsomedial nucleus maintains a strong GABAergic projection to the PVN that is directly activated by stressful stimuli (Cullinan et al., 1995, 1996). Lesions of the arcuate nucleus increase stress-induced corticosterone secretion (Magarinos et al., 1988; Larsen et al., 1994), suggestive of an inhibitory role of this region in PVN regulation. Electrophysiological studies note that neurons in the peri-PVN region and perifornical nucleus inhibit neuronal activity of medial parvocellular PVN neurons (Boudaba et al., 1996). Finally, neurons in the anterior subdivisions of the BST are involved in increased CRH mRNA expression seen after anterior BST lesions (Herman et al., 1994). Thus, all PVN-projecting regions showing increased GAD expression after stress have been associated with HPA regulation, strengthening the hypothesis that GABAergic neurons contained in these areas play an important role in inhibition of the stress axis.
Exposure to stress results in distinct patterns of GAD65 and GAD67 mRNA upregulation. In the case of acute stress, GAD67 appears to be preferentially induced. The number of regions showing upregulation of GAD67 mRNA is substantially more widespread than that of GAD65. Induction of GAD67 is rapid and transient, occurring at $1 \mathrm{hr}$ of stimulation and returning to levels indistinguishable from baseline within $2 \mathrm{hr}$ of stress induction. The limited effects of acute stress on GAD65 mRNA levels (BST and dentate gyrus only) suggest that this gene is less responsive than GAD67; however, it is also possible that induction of the GAD65 gene may occur more slowly and thus not be visible in the present study. The rapid activation and inactivation of GAD67 mRNA expression suggests transcriptional regulation by immediate early genes; indeed, it is important to note that all regions showing GAD67 upregulation express cFOS after restraint (Cullinan et al., 1995), consistent with transcriptional activation by AP-1.

In contrast to GAD67 mRNA, GAD65 mRNA is preferentially activated by prolonged stress exposure. After a 2 week exposure to chronic intermittent stress, rats show pronounced increases in 

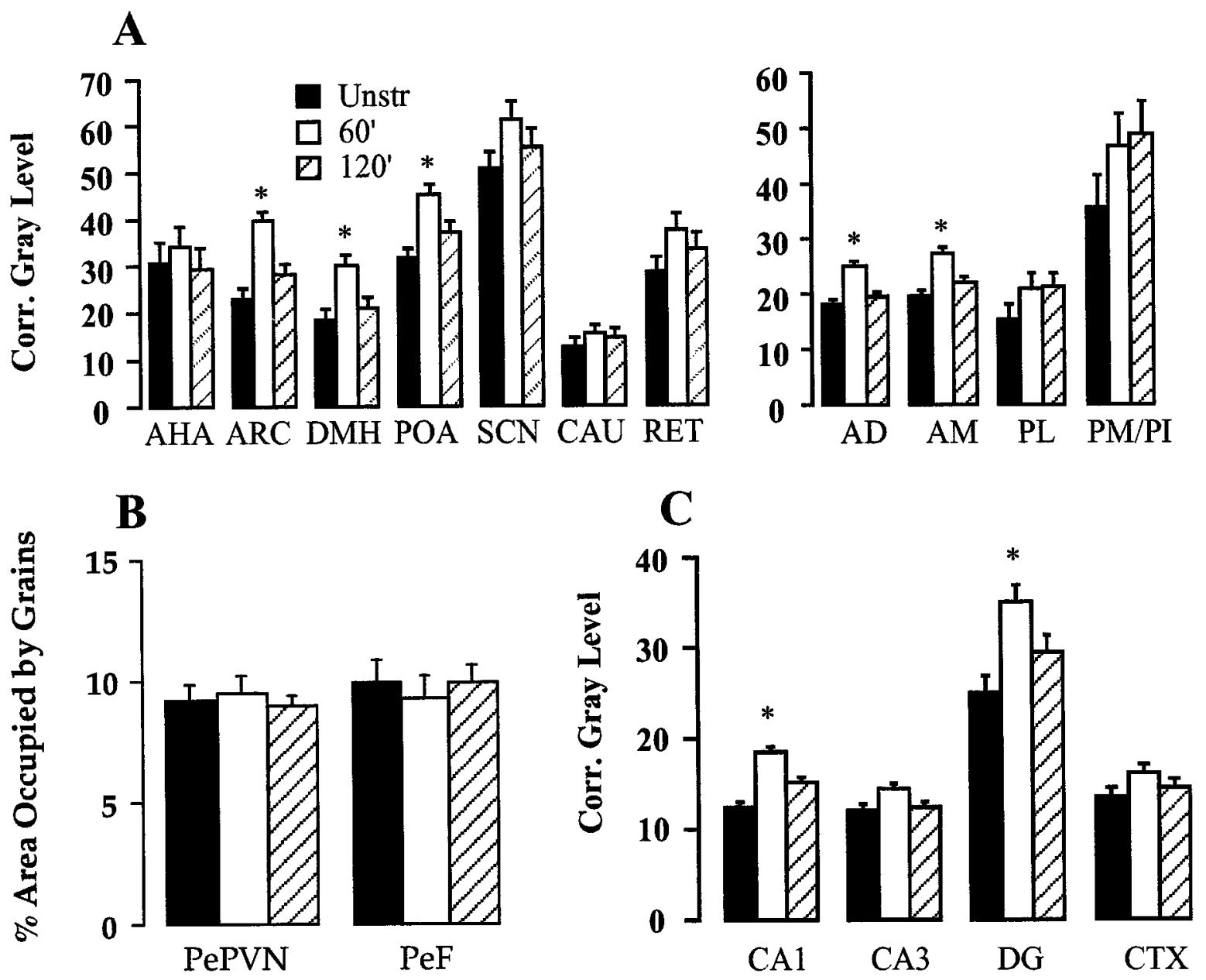

Figure 4. Semiquantitative assessment of the effect of acute restraint on GAD67 mRNA expression in forebrain stress-relevant nuclei. $A$, In contrast with GAD65 mRNA, GAD67 mRNA was elevated in the $A R C, D M H$, medial $P O A$, and anterodorsal and anteromedial BST 60 min after initiation of stress. In all cases, GAD67 mRNA levels returned to baseline by $120 \mathrm{~min}$. $B$, No changes in GAD67 grain density were observed over neurons in the peri-PVN region or $P e F$ after acute stress. $C$, GAD67 mRNA was elevated in the hippocampal subfield $C A 1$ and $D G 60$ min after stress initiation. Abbreviations are given in the Figure 3 legend.

GAD65 mRNA expression in most of the same cell groups manifesting increased GAD67 expression with acute stress (i.e., medial preoptic area, dorsomedial nucleus, and anterodorsal and anteromedial BST). Increased GAD65 mRNA was also seen in PVN-projecting regions of the anterior hypothalamic area, periPVN zone, and perifornical nucleus. GAD67 upregulation was substantially more limited, being confined to the anterodorsal and anteromedial BST and medial preoptic area.

Expression of GAD65 mRNA is slightly decreased in the immediate surround of the PVN $2 \mathrm{hr}$ after induction of acute restraint. Interestingly, this area is the only brain region to show decreased GAD expression after stress. This decrease may be related to heavy innervation of this region by GABAergic brain regions activated during stress, such as the lateral septum (Cullinan et al., 1995; Risold and Swanson, 1996). Evidence of chronic stress-induced increases in GAD65 mRNA expression in this region suggests that such inhibition may be overcome by prolonged stimulation.

\section{GAD65 and GAD67 mRNA regulation in non-PVN projecting loci}

Other stress-relevant regions, such as the suprachiasmatic nucleus and hippocampus, showed distinctive patterns of GAD65 and
GAD67 mRNA expression after acute and chronic stimulation. The suprachiasmatic nucleus is known to play a role in circadian regulation of corticosterone secretion (Cascio et al., 1987) and is implicated in inhibition of PVN activation by acute stress (Kalsbeck et al., 1992; Buijs et al., 1993a). The suprachiasmatic-PVN connection appears to be mediated by way of interneurons, perhaps in the subparaventricular zone (Watts et al., 1987; Buijs et al., 1993b), indicating a trans-synaptic influence. Upregulation of suprachiasmatic nucleus GAD mRNA expression was only observed after chronic stress and was specific for GAD65. It remains to be determined whether altered GABAergic neurotransmission may be involved in stress-induced disruption of circadian rhythms.

The hippocampus is known to inhibit the HPA axis (Jacobson and Sapolsky, 1991; Herman and Cullinan, 1997). Hippocampal actions appear to be trans-synaptic and may involve connections between hippocampal outflow neurons in the ventral subiculum and subcortical GABAergic pathways, notably including the medial preoptic area, BST, anterior hypothalamus, dorsomedial hypothalamic nucleus, and peri-PVN region (Cullinan et al., 1993; Herman et al., 1995). As such, it was of interest to determine whether hippocampal GAD was regulated in parallel with PVN- 

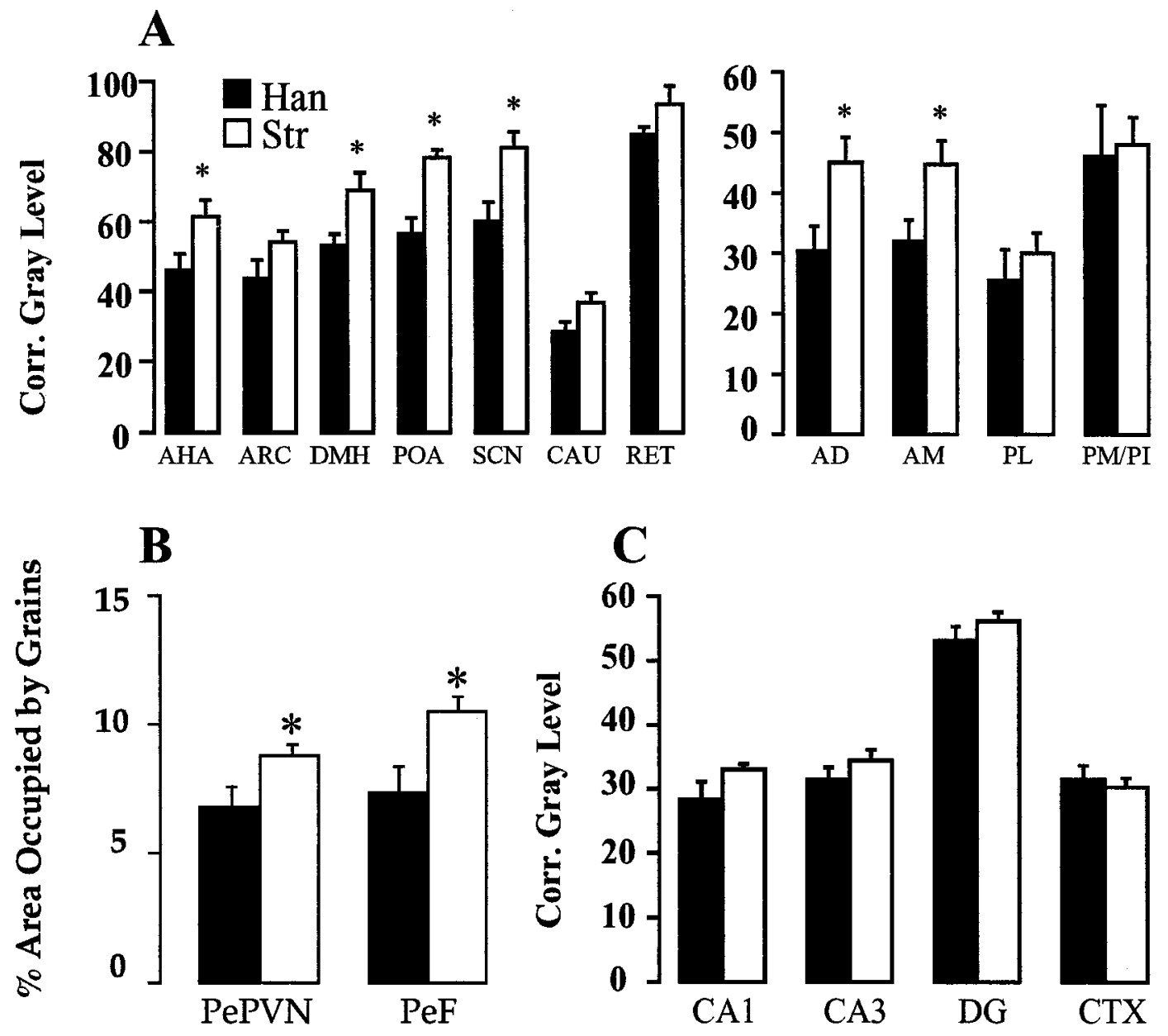

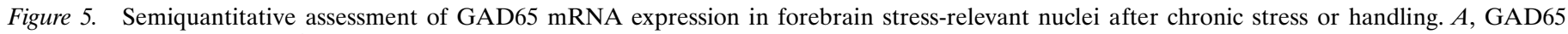

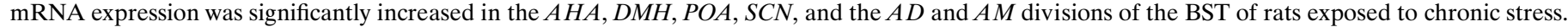

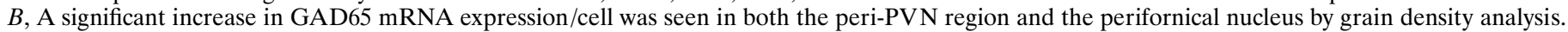

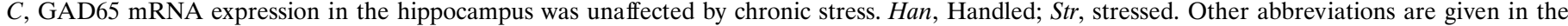
Figure 3 legend.

projecting hypothalamic and BST cell groups. In agreement with this notion, GAD67 mRNA is increased by acute stress in the CA1 and dentate gyrus. However, dentate gyrus GAD65 mRNA was also increased with acute stress, and chronic stress increased GAD67 mRNA in both CA3 and dentate gyrus. Thus, GAD regulation does not obey the same pattern in hippocampus as in the hypothalamic-BST continuum, indicating differential regulation among potential stress-regulatory pathways.

Notably, no changes in GAD65 or GAD67 mRNA were observed in the parietal cortex, caudate nucleus, or reticular thalamus. These regions have not been directly implicated in stress regulation, suggesting that stress-induced changes are not generalized throughout the nervous system. These data also verify that positive findings were not attributable to random variance in hybridization efficiency across sections. Thus, changes in GAD expression seem to be relegated to CNS pathways implicated in control of stress responsiveness.

\section{Differential regulation of GAD65 and GAD67 mRNA by acute and chronic stress: functional implications}

The distinctive induction of GAD65 and GAD67 mRNAs by chronic or acute stress, respectively, seems in keeping with the perceived role of the two isoforms in neuronal function. Approximately $50 \%$ of GAD65 appears as inactive apoenzyme (Kaufman et al., 1991). Much of GAD65 immunoreactivity is localized to nerve terminals, suggesting that GAD65 is stored in inactive form in presynaptic endings (Esclapez et al., 1994). This suggests that chronic stress-induced upregulation of GAD65 may increase apo-GAD stores, presumably to compensate for greater rates of stimulation. Conversely, GAD67 does not appear to be sequestered as an inactive apoenzyme and is enriched in neuronal cell bodies and dendrites (Kaufman et al., 1991; Esclapez et al., 1994). These data suggest the rate of GAD67 usage is higher than that of GAD65, given diminished localization in sites of storage (e.g., terminals) and the relative lack of detectable apo-GAD67. Upregulation of GAD67 mRNA by acute stress may thus reflect biosynthesis keyed to neuronal activity.

Precedent for physiological modulation of GAD65 and GAD67 mRNA expression has been noted in the literature. For example, striatal GAD67 mRNA and protein expression are upregulated after cortical ischemia (Salin and Chesselet, 1993). Striatal GAD activity and GAD67 mRNA levels are also increased after 6-hydroxydopamine lesion of the nigrostriatal pathway (Lindefors et al., 1989; Segovia et al., 1990). Interestingly, GAD65 and 

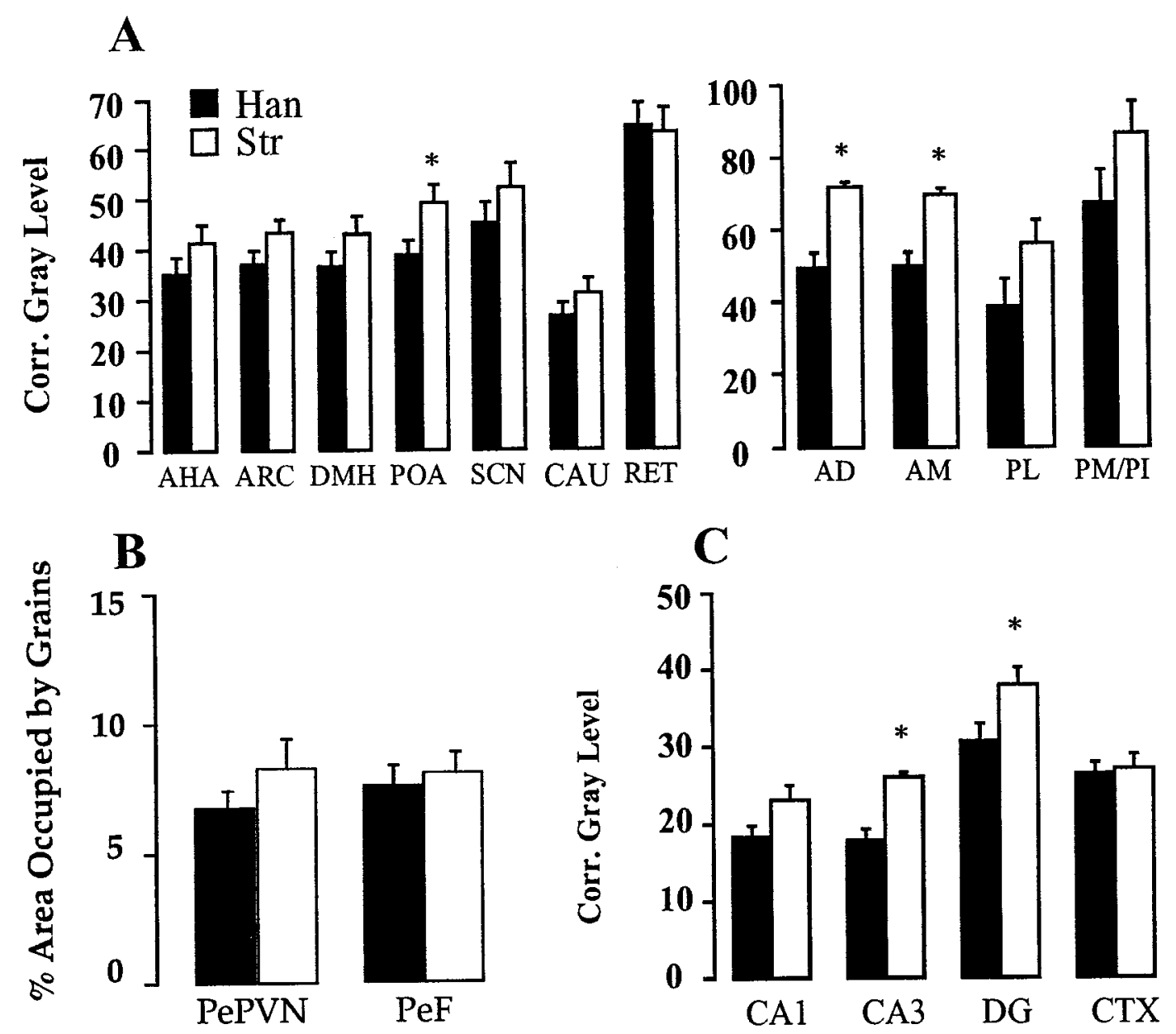

Figure 6. Semiquantitative assessment of GAD67 mRNA expression in forebrain stress-relevant nuclei after chronic stress or handling. $A$, Chronic stress induction of GAD65 mRNA expression was observed only in the medial $P O A$ and the $A D$ and $A M$ divisions of the BST of rats. $B$, No changes in GAD67 mRNA were seen in the peri-PVN region or perifornical nucleus by grain density analysis. $C$, Chronic stress exposure increased GAD67 mRNA expression in subfield $C A 3$ of the hippocampus and in the $D G$. Abbreviations are given in the legends of Figures 3 and 5.

GAD67 mRNAs are differentially regulated in this model system; in general, changes in GAD65 mRNA are more circumscribed than are those in GAD67 mRNA, showing no induction in the striatum (Soghomonian et al., 1992) and minimal induction (relative to GAD67) in the thalamic reticular nucleus, a downstream target of striatal efferents (Delfs et al., 1996). Pharmacological analyses indicate that long-term treatment with neuroleptic drugs increases GAD67 mRNA expression in the entopeduncular nucleus and globus pallidus (Mercugliano et al., 1992), further consistent with an integral role for GABA in extrapyramidal regulation. In the cerebellum, neurotoxic lesions of the climbingfiber pathway increased GAD67 mRNA expression and GAD activity in Purkinje cell populations (Litwak et al., 1990), indicating induction of GAD67 gene transcription by cellular activity. Nonetheless, changes in GAD67 mRNA occur after chronic stimulation, indicating that GAD expression is capable of responding dynamically to changes in activity in multiple neuronal systems.

In the present study, long-term stress exposure does not affect expression of GAD67 mRNA in the majority of the stress-related regions examined; rather, chronic stress seems to differentially increase expression of GAD65 mRNA. These results suggest that, unlike the extrapyramidal system and cerebellum, activity- dependent upregulation of GAD in stress pathways occurs via increased expression of GAD65 mRNA. Alternatively, this difference may also reflect a greater sensitivity of the GAD65 gene to induction by stress; GAD67 mRNA induction may require the more prolonged and consistent stimulation afforded by lesion or pharmacological stimulation.

Induction of GAD by stress has important implications for HPA regulation. First, regions showing GAD induction correspond with those showing cFOS expression after stress (Cullinan et al., 1996). These neural populations also contain inhibitory neuropeptides, including CRH (Champagne et al., 1998), further supporting inhibitory actions on HPA activity. Together, these data suggest that BST and hypothalamic GABAergic cell populations are activated by stress and are likely to convey inhibition to the PVN. Second, hypothalamic and BST neurons are in a position to interconnect regions such as the hippocampus and amygdala with the PVN (Price et al., 1987; Swanson, 1987; Swanson et al., 1987). Thus, this collection of GABAergic neurons may translate limbic output into appropriate integration of stress responses. Connections between PVN-projecting neuronal populations and extrahypothalamic glucocorticoid-receptive sites (e.g., the hippocampus/ventral subiculum) (Herman, 1993) also raise the possibility that GABA may play a role in translating glucocorticoid 
feedback signals into PVN inhibition. Third, induction of GAD65 mRNA is consistent with a role for GABA in attenuating activation of the HPA axis in the face of chronic drive. Increased GAD65 mRNA availability predicts increased GAD65 levels, which may stand to enhance inhibition at the PVN. Finally, induction of GAD in the hippocampus suggests that local GABA may modulate cognitive function after stress. Stress is known to have deleterious effects on learning and memory (Luine et al., 1993; Diamond and Rose, 1994; Diamond et al., 1994) and induces dendritic atrophy in subfield CA3 (Magarinos and McEwen, 1995). The observed increases in GAD expression in the hippocampus raises the possibility that altered inhibition may contribute to stress-induced behavioral changes.

In summary, GABA mRNA synthesis is specifically increased in PVN-projecting brain regions after acute and chronic stress exposure. Acute increases in GAD67 are likely keyed toward replenishing GABA released after stimulation, whereas chronic increases in GAD65 may serve to attenuate the effects of repetitive stimulation on central stress circuitry. The results point toward a prominent role for GABAergic pathways in central stress integration.

\section{REFERENCES}

Antoni FA (1986) Hypothalamic control of adrenocorticotropin secretion: advances since the discovery of 41-residue corticotropin-releasing factor. Endocr Rev 7:351-378.

Boudaba C, Szabo K, Tasker JG (1996) Physiological mapping of local inhibitory inputs to the hypothalamic paraventricular nucleus. J Neurosci 16:7151-7160.

Buijs RM, Kalsbeek A, van der Woude TP, van Heerikhuize JJ, Shinn S (1993a) Suprachiasmatic nucleus lesion increases corticosterone secretion. Am J Physiol 264:R1186-R1192.

Buijs RM, Markman M, Nunes CB, Hou YX, Shinn S (1993b) Projections of the suprachiasmatic nucleus to stress-related areas in the rat hypothalamus: a light and electron microscopic study. J Comp Neurol 335:42-54.

Cascio CS, Shinsako J, Dallman MF (1987) The suprachiasmatic nuclei stimulate evening ACTH secretion in the rat. Brain Res 423:173-178.

Champagne D, Beaulieu J, Drolet G (1998) CRFergic innervation of the paraventricular nucleus of the rat hypothalamus: a tract-tracing study. J Neuroendocrinol 10:119-131.

Cullinan WE, Herman JP, Watson SJ (1993) Ventral subicular interaction with the hypothalamic paraventricular nucleus: evidence for a relay in the bed nucleus of the stria terminalis. J Comp Neurol 332:1-20.

Cullinan WE, Herman JP, Battaglia DF, Akil H, Watson SJ (1995) Pattern and time course of immediate early gene expression in rat brain following acute stress. Neuroscience 64:477-505.

Cullinan WE, Helmreich D, Watson SJ (1996) Fos expression in forebrain afferents to the hypothalamic paraventricular nucleus following swim stress. J Comp Neurol 368:88-99.

Delfs JM, Ciaramitaro VM, Soghomonian JJ, Chesselet MF (1996) Unilateral nigrostriatal lesions induce a bilateral increase in glutamate decarboxylase messenger RNA in the reticular thalamic nucleus. Neuroscience 71:383-395.

Diamond DM, Rose GM (1994) Stress impairs LTP and hippocampaldependent memory. Ann NY Acad Sci 746:411-414.

Diamond DM, Fleshner M, Rose GM (1994) Psychological stress repeatedly blocks hippocampal primed burst potentiation in behaving rats. Behav Brain Res 62:1-9.

Esclapez M, Tillakaratne NJK, Tobin AJ, Houser CR (1993) Comparative localization of mRNAs encoding two forms of glutamic acid decarboxylase with nonradioactive in situ hybridization methods. J Comp Neurol 331:339-362.

Esclapez M, Tillakaratne NJK, Kaufman DL, Tobin AJ, Houser CR (1994) Comparative localization of two forms of glutamic acid decar boxylase and their mRNAs in rat brain supports the concept of functional differences between the forms. J Neurosci 14:1835-1855.

Feldblum S, Erlander MG, Tobin AJ (1993) Different distributions of$\mathrm{GAD}_{65}$ and $\mathrm{GAD}_{67}$ mRNAs suggest that the two glutamate decarboxylases play distinctive functional roles. J Neurosci Res 34:689-706.

Herman JP (1993) Regulation of adrenocorticosteroid receptor mRNA expression in the central nervous system. Cell Mol Neurobiol 13:349-372.

Herman JP, Cullinan WE (1997) Neurocircuitry of stress: central control of the hypothalamo-pituitary-adrenocortical axis. Trends Neurosci 20:78-83.

Herman JP, Schäfer MK-H, Young EA, Thompson R, Douglass J, Akil H, Watson SJ (1989) Evidence for hippocampal regulation of neuroendocrine neurons of the hypothalamo-pituitary-adrenocortical axis. J Neurosci 9:3072-3082.

Herman JP, Cullinan WE, Watson SJ (1994) Involvement of the bed nucleus of the stria terminalis in tonic regulation of paraventricular hypothalamic CRH and AVP mRNA expression. J Neuroendocrinol 6:433-442.

Herman JP, Cullinan WE, Morano MI, Akil H, Watson SJ (1995) Contribution of the ventral subiculum to inhibitory regulation of the hypothalamo-pituitary-adrenocortical axis. J Neuroendocrinol 7:475-482.

Jacobson L, Sapolsky RM (1991) The role of the hippocampus in feedback regulation of the hypothalamo-pituitary-adrenocortical axis. Endocr Rev 12:118-134.

Kalsbeck A, Buijs RM, van Heerikhuize J, Arts M, van der Woude TP (1992) Vasopressin-containing neurons of the suprachiasmatic nuclei inhibit corticosterone release. Brain Res 580:62-67.

Kaufman DL, Houser CR, Tobin AJ (1991) Two forms of the gammaaminobutyric acid synthetic enzyme glutamate decarboxylase have distinct intraneuronal distributions and cofactor interactions. J Neurochem 56:720-723.

Larsen PJ, Mikkelsen JD, Jessop D, Lightman SL, Chowdrey HS (1994) Neonatal monosodium glutamate treatment alters both the activity and the sensitivity of the rat hypothalamo-pituitary-adrenocortical axis. J Endocrinol 141:497-503.

Lindefors N, Brene S, Herrera-Marschitz M, Persson H (1989) Region specific regulation of glutamic acid decarboxylase mRNA expression by dopamine neurons in rats brain. Exp Brain Res 77:611-620.

Litwak J, Mercugliano M, Chesselet M-F, Oltmans GA (1990) Increased glutamic acid decarboxylase (GAD) mRNA and GAD activity in cerebellar Purkinje cells following lesion-induced increases in cell firing. Neurosci Lett 116:179-183.

Luine V, Villegas M, Luine VN, McEwen BS (1993) Repeated stress causes reversible impairments of spatial memory performance. Brain Res 639:167-170.

Magarinos AM, McEwen BS (1995) Stress-induced atrophy of apical dendrites of hippocampal CA3 neurons: comparison of stressors. Neuroscience 69:83-88.

Magarinos AM, Estivariz F, Morano MI, de Nicola AF (1988) Regulation of the central nervous system-pituitary-adrenal axis in rats after neonatal treatment with monosodium glutamate. Neuroendocrinology 48:105-111.

Mercugliano M, Saller CF, Salama AI, U-Prichard DC, Chesselet M-F (1992) Clozapine and haloperidol have differential effects on glutamic acid decarboxylase mRNA in the pallidal nuclei of the rat. Neuropsychopharmacology 6:179-187.

Paxinos G, Watson C (1986) The rat brain in stereotaxic coordinates. New York: Academic.

Price JL, Russchen FT, Amaral DG (1987) The limbic region. II. The amygdaloid complex. In: Handbook of chemical neuroanatomy (Björklund A, Hökfelt T, Swanson LW, eds), pp 279-388. Amsterdam: Elsevier.

Risold PY, Swanson LW (1996) Structural evidence for functional domains in the rat hippocampus. Science 272:1484-1486.

Salin P, Chesselet M-F (1993) Expression of GAD (Mr 67,000) and its messenger RNA in basal ganglia and cerebral cortex after ischemic cortical lesions in rats. Exp Neurol 119:291-301.

Sawchenko PE, Brown ER, Chan RWK, Ericsson A, Li H-Y, Roland BK, Kovacs KJ (1996) The paraventricular nucleus of the hypothalamus and the functional neuroanatomy of visceromotor responses to stress. Prog Brain Res 107:201-222.

Segovia J, Tillakaratne NJ, Whelan K, Tobin AJ, Gale K (1990) Parallel increases in striatal glutamic acid decarboxylase activity and mRNA 
levels in rats with lesions of the nigrostriatal pathway. Brain Res 529:345-348.

Soghomonian JJ, Gonzales C, Chesselet MF (1992) Messenger RNAs encoding glutamate-decarboxylases are differentially affected by nigrostriatal lesions in subpopulations of striatal neurons. Brain Res $576: 68-79$.

Swanson LW (1987) The hypothalamus. In: Handbook of chemical neuroanatomy (Björklund A, Hökfelt T, Swanson LW, eds), pp 1-124. Amsterdam: Elsevier.

Swanson LW, Köhler C, Björklund A (1987) The limbic region. I. The septohippocampal system. In: Handbook of chemical neuroanatomy (Björklund A, Hökfelt T, Swanson LW, eds), pp 125-277. Amsterdam: Elsevier.
Viau V, Meaney MJ (1996) The inhibitory effect of testosterone on hypothalamo-pituitary-adrenal responses to stress is mediated by the medial preoptic area. J Neurosci 16:1866-1876.

Walaas I, Fonnum F (1980) Biochemical evidence for glutamate as a transmitter in hippocampal efferents to the basal forebrain and hypothalamus in the rat brain. Neuroscience 5:1691-1698.

Watts AG, Swanson LW, Sanchez-Watts G (1987) Efferent projections of the suprachiasmatic nucleus: studies using anterograde transport of phaseolus vulgaris-leucoagglutinin in the rat. J Comp Neurol 258:204-229.

Whitnall MH (1993) Regulation of the hypothalamic corticotropinreleasing hormone neurosecretory system. Prog Neurobiol 40:573-629. 